\title{
EFEITOS DO DANO ORIUNDO DE INADIMPLEMENTO CULPOSO DO CONTRATO DE EMPREITADA
}

\section{EFFECTS OF THE DAMAGE CAUSED BY THE CULPABLE DEFAULT IN THE CONSTRUCTION CONTRACTS}

MARIA HELENA DINIZ

Mestre e Doutora em Teoria Geral do Direito e Filosofia do Direito pela Pontifícia Universidade Católica de São Paulo - PUCSP. Livre Docente e Titular de Direito Civil da Pontifícia Universidade Católica de São Paulo - PUCSP, por concurso de títulos e provas. Professora de Direito Civil no Curso de Graduação da Pontifícia Universidade Católica de São Paulo - PUCSP. Professora de Filosofia do Direito, de Teoria Geral do Direito e de Direito Civil Comparado nos Cursos de Pós-Graduação (mestrado e doutorado) em Direito da Pontifícia Universidade Católica de São Paulo - PUCSP. Coordenadora do Núcleo de Pesquisa em Direito Civil Comparado nos Cursos de Pós-Graduação em Direito da Pontifícia Universidade Católica de São Paulo - PUCSP. Membro da Academia Paulista de Direito (cadeira 62-patrono Oswaldo Aranha Bandeira de Mello); da Academia Notarial Brasileira (cadeira 16 patrono Francisco Cavalcanti Pontes de Miranda), do Instituto dos Advogados de São Paulo e do Instituto de Direito Comparado Luso-brasileiro. Presidente do Instituto Internacional de Direito (IID).

\section{RESUMO}

Metodologia: Para atingir ao que se pretende transmitir, cientificamente, neste artigo, a metodologia utilizada foi a lógico-dialética, tendo por suporte a análise de referências bibliográficas, da legislação brasileira, principalmente, do Código Civil de 2002 e de decisões judiciais como as do Superior Tribunal de Justiça. 
Resultados: O artigo aponta, se uma das partes vier a ser indenizada, em virtude de descumprimento de contrato de empreitada por culpa de outra, as seguintes consequências jurídicas: inexistência de enriquecimento ilícito e descabimento de propositura de ação in rem verso. Ressalta, ainda, a relevância da boa fé na apuração da responsabilidade indenizatória, sendo que o valor da indenização estipulado por expert deverá ter por baliza a repercussão econômica do contrato descumprido no patrimônio do lesado.

Contribuições: A principal contribuição deste trabalho consiste em demonstrar o cabimento da aplicação do art. 475 do Código Civil e de algumas consequências decorrentes do inadimplemento culposo da empreitada, tais como: resolução contratual, indenização por perdas e danos tendo por parâmetro o próprio contrato, na forma de lucros cessantes e da perda de uma chance, liberação de reparação de danos emergentes se a parte arcar com os custos.

Palavras-chave: Empreitada; Validade Negocial; Descumprimento Voluntário; Responsabilidade Civil; Perda de uma chance; Quantificação do Dano.

\section{ABSTRACT}

Methodology: To achieve what it is intended to convey, scientifically, in this article, the methodology used was the logical-dialectic, supported by the analysis of bibliographic references, of the Brazilian legislation, mainly of the Civil Code of 2002 and of judicial decisions such as of the Superior Court of Justice.

Results: The article points out the following legal consequences, if one of the parties is indemnified, due to noncompliance with the contract for the fault of another: no graft and misplaced action in rem verso. It also emphasizes the relevance of good faith in civil liability application, and the amount of indemnity stipulated by an expert should be based on the economic repercussion of the breached contract in the injured party's assets.

Contributions: The main contribution of this work is to demonstrate the appropriateness of the application of art. 475 of the Civil Code and some consequences resulting from the beach of the contract, such as termination of the contract, indemnity for losses and damages having as parameter the contract itself, in the form of loss of profits and the loss of a chance, damage repair release if the party bears the costs.

Keywords: Contract; Contractual Validity; Voluntary Non-Compliance; Civil Liability; Loss of a chance; Damage Quantification. 


\section{INTRODUÇÃO: NATUREZA JURÍDICA DO CONTRATO E QUESTÃO DE SUA VALIDADE}

Suponha-se que uma empresa "A" de construção civil, ao destacar-se no mercado, passe a fazer uso de seus serviços, celebrando um contrato com "B" para construção de empreendimentos imobiliários de baixa renda, comprometendo-se a executar a construção, contribuindo com seu trabalho, administração e técnica de obra, mediante o pagamento da obra realizada e o financiamento de compra de material. "A empresa "C" procura a empresa "B" propondo vantagens; com isso a empresa "B" propõe à empresa "A" para que esta não venha fornecer à empresa "C" a entrega de " $x$ " unidades imobiliárias para serem construídas em 5 anos, desde que tenha exclusividade de atuação nesse segmento de construção.

A empresa "B" descumpre o prometido e a empresa "A" teve um grande prejuízo e, por este motivo, pediu a resolução do contrato e a indenização por perdas e danos (Código Civl, art. 475), visto que empresa "B":

a) não the ofereceu o número mínimo de unidades imobiliárias que havia prometido;

b) não Ihe pagou a remuneração das unidades não ofertadas;

c) Ihe retirou, ao exigir exclusividade, a chance de negociar com outras empresas, impedindo-a de competir no ramo de construção civil para a baixa renda;

d) violou os princípios da boa-fé objetiva, confiança, eticidade, função social do contrato e livre concorrência (Código Civil, art. 422; Constituição, art. $3^{\circ}$., inciso I).

A empresa "A" pleiteou avaliação das perdas e danos, em laudo pericial, baseado no contrato, ou melhor, no número de unidades imobiliárias não entregues, multiplicado pelo valor médio de uma unidade, tendo por base a cláusula contratual que estabelece o percentual de remuneração (lucro) de $16 \%$, calculado com base no custo médio de cada unidade, multiplicado pelo número de unidades a que a empresa "B" estava obrigada, não abrangendo o custo raso da obra (despesas feitas em cada empreendimento para pagamento de fornecedor, terceiros e funcionários). 
Como todo negócio jurídico, o contrato origina-se de ato volitivo, com o escopo de obter certo objetivo, criando, com base em norma jurídica, direito subjetivo e impondo, por outro lado, obrigações jurídicas.

No caso hipotético descrito, configurado está o contrato de empreitada, pelo qual um dos contratantes (empreiteiro) obriga-se sem subordinação a realizar certa obra para outro com material próprio ou por este fornecido (empreiteira de lavor), mediante uma remuneração determinada ou proporcional ao trabalho executado (GOMES, 1979, p.359; DINIZ, 2018, p.325 e ss; PONTES DE MIRANDA, 1984, p.375 e ss).

Trata-se de um contrato de execução continuada por necessitar de certo espaço de tempo para sua conclusão, dada a própria estrutura de seu objeto: a efetivação de um trabalho para atingir certo resultado. Realiza-se por uma série concatenada de atos, podendo gerar riscos de seu inadimplemento por culpa das partes, caso fortuito e força maior.

Um dos contratantes (Empresa "B") veio a alegar vício formal do contrato por haver assinatura de apenas um representante da pessoa jurídica, visto que o estatuto requer assinatura de dois procuradores, salvo para prática de atos de mera rotina administrativa. Tal vício não é de nulidade absoluta por não ferir as hipóteses arroladas no Código Civil, art. 166, incisos IV e V. Houve inobservância da forma prevista estatutariamente e não da forma legal.

Nos termos do art. 171 do Código Civil, no exemplo dado, de nulidade relativa, suscetível de ratificação, uma vez que o contrato de empreitada não exige forma especial, podendo ser celebrado oralmente ou por escrito. Foram praticados atos indicativos de início da execução do contrato por ambas as partes, convalidando-o (Código Civil, arts. 172 a 175).

É preciso, ainda, ressaltar que, ante o princípio da conservação negocial, dever-se-á aproveitar o negócio, para proteger aquele que, de boa-fé, confiou na estabilidade da relação jurídica e para prestigiar a função social do contrato.

Sob a égida do art. 175 do Código Civil, a confirmação expressa ou a execução voluntária de negócio anulável, importa a extinção de todos as ações ou exceções que contra ele houverem. 
Deveras, se $o$ ato negocial for passível de anulação, o lesado poderá lançar mão de uma ação, mas com a confirmação, subentende-se que houve extinção de qualquer providência que pudesse obter a decretação judicial de nulidade relativa. $A$ confirmação dará origem à desistência ou renúncia ao direito de anular negócio viciado. Com a confirmação do contrato, não mais será possível anulá-lo, embora viciado, pois a nulidade relativa deixou de existir ante a irrevogabilidade dos atos confirmatórios, que validaram a obrigação contratual em definitivo. Logo, seu efeito é ex tunc, tornando válido o negócio desde sua formação. Sendo válido, deverá ser cumprido pelos interessados.

\section{DESCUMPRIMENTO CONTRATUAL VOLUNTÁRIO}

Nítido é o caráter vinculante do contrato, apontado como exemplo, de a empresa "B" entregar o número mínimo de unidades imobiliárias à empresa "A", consignadas ano a ano, que é reforçado com o estabelecimento do limite de tolerância de $10 \%$ do número anual de unidades imobiliárias contratadas para construção e com o direito de preferência em relação a terceiros; que criou para a empresa "B" o dever de apresentar melhor orçamento para a empresa "A", para que esta pudesse igualá-lo para obter a contratação. E, além disso, havia previsão de cláusula de exclusividade para todo o período de vigência do contrato, que seria liberada na hipótese de um ano de descumprimento do dever pela empresa "B". A empresa "B" inadimpliu o contrato ao vender seu controle para outra empresa, tornando-se uma das maiores construtoras do setor de baixa renda, dando início à construção das mesmas unidades prometidas à empresa "A" com outras construtoras, olvidando o seu direito de preferência.

Caracterizado ficou o inadimplemento culposo negocial, pois a empresa "B" não entregou a empresa "A" o número mínimo de unidades imobiliárias para construção em 5 anos, não the pagou a remuneração fixada, nem deu preferência em relação a terceiros e, ainda, vinculou-a a uma cláusula de exclusividade, 
deixando-a fora do mercado, sem poder atender a outra incorporadora e sem poder construir, pois a empresa "B" não lhe atribuiu todas as unidades para construção.

O descumprimento voluntário do contrato pela empresa "B" gera indenização em favor da empresa "A", oriunda de responsabilidade civil contratual.

A empresa "A" deixou de ganhar remuneração e os lucros a que teria direito se a empresa "B" tivesse cumprido o contrato e perdeu a chance de contratar com outras incorporadoras, em razão da cláusula de exclusividade que a coibia de atuar livremente em ramo de construção civil de baixa renda.

Houve inexecução culposa da empresa "B", sem a dirimente do caso fortuito ou força maior, devendo por isso responder pelas perdas e danos (Código Civil, art. 389) e pela perda da chance que é indenizável ante a certeza de existência de chance perdida pela empresa "A" por ato culposo da empresa "B".

A empresa "A", em virtude de cláusula de exclusividade, perdeu a oportunidade de tornar-se uma grande construtora para o mercado de incorporação de obras e acabou sendo eliminada do mercado imobiliário para a construção de empreendimento para baixa renda, pois perdeu a chance de contratar com outras incorporadoras. Com a chance perdida, com o fechamento das portas do mercado, a empresa "A" teve, obviamente, de arcar com os cursos para sua sobrevivência. A empresa lesada (A) poderá pleitear resolução contratual, indenizatória das perdas e danos (Código Civil, arts. 389 e 475) e pela perda da chance.

Cita-se o Enunciado 31, aprovado na I Jornada de Direito Civil: "As perdas e danos mencionados no art. 475 dependem da imputabilidade da causa da possível resolução". Como não há excludente da força maior e de caso fortuito, o art. 475 é aplicável ao caso exemplificado. Pelo Enunciado 361 da IV Jornada de Direito Civil: "O adimplemento substancial decorre dos princípios gerais contratuais, de modo a fazer preponderar a função social do contrato (Código Civil, art. 421) e o princípio da boa-fé objetiva (Código Civil, art. 422), balizando a aplicação do art. 475".

Ora a empresa "B" feriu o princípio da boa-fé objetiva e causou a necessidade de resolução do contrato, que é denotada mais pela quebra de confiança do que pelo não cumprimento da entrega do número mínimo de unidades imobiliárias. 
A boa-fé objetiva prevista no art. 422 é atinente a um padrão comportamental a ser seguido, baseado na lealdade e na probidade (integridade de caráter), proibindo comportamento contraditório, impedindo o exercício abusivo de direito por parte dos contratantes, no cumprimento da obrigação principal e das acessórias e do dever de informar, de colaborar e de atuação diligente. A empresa "B" não agiu de conformidade com esse princípio.

A empresa "A", tendo sido lesada pelo inadimplemento culposo contratual, poderá pedir resolução do contrato, se não preferir exigir-lhe o cumprimento, cabendo em qualquer dos casos, indenização por perdas e danos (Código Civil, art. 475).

Pelos prejuízos da empresa "A", sujeitar-se-á a empresa "B" ao dever de reparar as perdas e danos sofridos, pois o prejuízo decorrente do não cumprimento do contrato é pressuposto da responsabilidade civil contratual.

\section{FUNÇÃO DA RESPONSABILIDADE CIVIL NO INADIMPLEMENTO CULPOSO DO CONTRATO}

Grande é a importância da responsabilidade civil, por se dirigir à restauração de um equilíbrio moral e/ou patrimonial desfeito e à redistribuição da riqueza, de conformidade com os ditames da justiça, tutelando a pertinência de um bem, com todas as utilidades presentes e futuras, a um sujeito determinado.

A responsabilidade civil é a aplicação de medidas que obriguem uma pessoa a reparar o dano causado a outrem.

$O$ interesse em restabelecer o equilíbrio violado pelo dano é a fonte geradora da responsabilidade, consistente na reposição do lesado à situação anterior à lesão, por meio de uma reconstituição natural ou de uma indenização, que represente do modo mais exato possível o valor do prejuízo no momento de seu ressarcimento ${ }^{1}$.

${ }^{1}$ Vide: DE CUPIS, 2018. p. 21-26. 
A responsabilidade civil constitui uma sanção civil, por decorrer de infração de lei ou de contrato, cujo objetivo é o interesse particular e, em sua natureza, é compensatória por abranger reparação do dano causado, punindo o lesante e desestimulando a prática de atos lesivos.

Ora a empresa "B" descumpriu culposamente o contrato, logo, deverá arcar com as consequências de sua responsabilidade civil.

Como houve inexecução do contrato, a empresa "A" terá direito a uma reparação que possibilite reequilibrar sua posição jurídica, ressarcindo-Ihe todos os prejuízos, mediante estimação das perdas e danos e da chance perdida.

\section{CONSEQUÊNCIAS DO DANO CAUSADO POR CONDUTA CULPOSA DO CONTRATANTE}

A culpa da empresa "B" gera responsabilidade civil contratual e, consequentemente, indenização por perdas e danos e pela perda de uma chance, por ferir a boa-fé objetiva.

O dano não é hipotético, como vimos, mas real. Após várias tentativas de obter o cumprimento da obrigação pela empresa "B", a empresa "A" pode, com base no art. 475 do Código Civil, pedir cumulação da resolução contratual com perdas e danos, pois foi lesada pelo inadimplemento culposo do contrato.

Como não houve cumprimento voluntário do contrato pela empresa "B", o art. 475 do Código Civil permite que haja, em favor da empresa "A", cumulação da resolução do contrato válido, com uma indenização pelo interesse, seja ele positivo ou negativo, que está ligado ao objeto da obrigação inadimplida.

Se a empresa A" pedir a resolução do contrato, liberando-se da obrigação de construir, não pretende desistir da indenização a que tem direito, que a colocaria na mesma situação em que estaria com o adimplemento do contrato.

Isto é assim, porque a empreitada diferencia-se de outras formas congêneres, uma vez que nela se avença o resultado de sua consecução, mas não se poderá concluir que, uma vez iniciada a execução contratual, será levada a cabo 
de forma absoluta. Por tal razão, o inadimplemento culposo da incorporadora fará com que o empreiteiro tenha direito a uma indenização correspondente ao dano emergente e aos lucros cessantes e também à chance perdida.

Quais as perdas e danos cabíveis à empresa "A", em razão do inadimplemento culposo do contrato pela empresa "B"?

Abrange além do dano emergente, o lucro cessante ${ }^{2}$. O lucro cessante visa repor, no patrimônio da empresa "A", a vantagem econômica que, razoavelmente, auferiria se a empresa "B" tivesse cumprido a obrigação assumida no contrato.

Pelo art. 623 do Código Civil, que disciplina os lucros cessantes decorrentes da resilição antecipada abrupta e unilateral, a empresa "A", frustrada a conclusão do contrato, teria direito às despesas e lucros relativos aos serviços já feitos, mais indenização razoável, calculada em função do que ele teria ganho se concluída a obra.

A execução da obra frustrada sem justa causa, pela empresa "B", assegura à empresa "A" o direito à resolução do contrato e à indenização dos lucros que poderia ter tido se concluído o negócio. Tudo leva à procedência do pedido indenizatório no valor pretendido com base no contrato e na resolução negocial.

Isto porque a empresa "A" sofreu um dano que é a efetiva diminuição do seu patrimônio ao tempo em que ocorreu o inadimplemento culposo da obrigação pela empresa "B", consistindo na diferença entre o valor atual desse patrimônio e aquele que teria se a relação obrigacional fosse exatamente cumprida. É, portanto, a diferença entre a situação patrimonial atual, provocada pelo descumprimento da obrigação, e a situação em que a empresa "A" encontrar-se-ia, se não tivesse havido esse fato lesivo. Seriam as perdas e danos o equivalente do prejuízo suportado pela empresa "A" em virtude, de a empresa "B" não ter cumprido a obrigação, expressando-se numa soma de dinheiro correspondente ao desequilíbrio sofrido pela empresa "A".

2 Sobre perdas e danos: GIORGI, 1891, p. 137. POLACCO, 1915; LARENZ1958; CONSOLO, 1908; FISCHER, 1928. p. 1; DINIZ, 2018. p. 449 a 454. 
Pode haver demonstração pericial das perdas e danos, quantificando a indenização, que visa recompor a situação da empresa "A" ao estado em que estaria se não houvesse o inadimplemento substancial do contrato pela empresa "B".

Tal laudo pericial poderia apurar os ganhos decorrentes do contrato correspondente ao quea empresa "A" deixou de lucrar, tendo por base o negócio, abrangendo lucros cessantes e perda da chance.

Não haveria enriquecimento sem causa na cumulação da resolução com a indenização pelo interesse positivo porque houve:

a) inadimplemento culposo do contrato pela empresa "B" que gera pagamento de lucro cessante, ressarcindo o prejuízo suportado,

b) perda de lucros que teriam sido auferidos se o mínimo de unidades imobiliárias tivesse sido entregue nas datas avençadas.

Clara é a perda patrimonial da empresa "A", que procurava o lucro com o negócio frustrado e perdeu, ante a cláusula de exclusividade, a chance de negociar com outras incorporadoras e de crescer no mercado imobiliário.

Da leitura de todos os artigos (389, 402, 475, 623, 944, do Código Civil) vislumbra-se por interpretação sistemática o direito da empresa "A" a resolução do contrato e a indenização correspondente ao prejuízo causado pela conduta culposa da empresa "B" e pela perda da chance perdida.

Logo, o valor do quantum indenizatório poderá ser alto, mas não causará enriquecimento ilícito, por refletir justa indenização baseada no contrato e por ter frustrado um projeto para o futuro. Tal quantum é decorrente de inadimplemento culposo e substancial da empresa " $B$ " que dá origem à resolução do contrato, que causa, além de dano emergente e lucros cessantes (STJ, 3ํT, REsp 151175/DF-rel Min. Waldemar Zveiter, j. 15.12.1998), uma indenização por perda de uma chance.

O Código Civil, art. 944, exige que se averigue a real extensão do dano. A lesada poderá abrir mão das unidades imobiliárias, pleiteando tão somente a indenização por lucros cessantes, ou seja, aquilo que deixou de ganhar, por causa do inadimplemento do contrato e pela perda de uma chance.

Será que houve configuração da perda de uma chance? 


\section{POSSÍVEL CONFIGURAÇÃO DA PERDA DE UMA CHANCE}

A chance é parte integrante do patrimônio da pessoa, por ser a possibilidade de obtenção de uma vantagem ou de evitar a ocorrência de um prejuízo.

A Perda da chance é a subtração de uma probabilidade ou esperança, ou seja, uma expectativa de se auferir um lucro ou de evitar evento danoso, sendo suscetível de avaliação econômica por gerar o dever de indenizar ${ }^{3}$. É o que decorre da interpretação sistemática do Código Civil, arts. 186, 187, 402, 927.

O "lucro cessante" ou dano negativo, alusivo à privação de um ganho pelo lesado, está condicionado a uma probabilidade objetiva, resultante de acontecimentos e, conjugado às circunstâncias peculiares do caso concreto, podendo ser não só um eventual benefício perdido como também perda da chance, ou seja, de oportunidade em que seria obtido um benefício, caso não houvesse o corte abrupto em decorrência do ilícito, que requer o emprego do tirocínio equitativo do órgão judicante, distinguindo a possibilidade de probabilidade e fazendo uma avaliação das perspectivas favoráveis, ou não, à situação do lesado, para atingir a proporção da reparação e deliberar seu quantum.

A perda da chance é um dano real indenizável se puder-se calcular o grau de probabilidade de sua concretização.

A perda de uma oportunidade é um dano cuja avaliação é difícil, por não ser possível a condução da vítima ao statu quo ante, pois não mais terá a chance perdida.

O lesado deve ser indenizado pelo equivalente daquela oportunidade, logo, o prejuízo terá um valor que variará conforme maior ou menor probabilidade de a chance perdida se concretizar.

\footnotetext{
${ }^{3}$ MARTINS COSTA, 2003. p. 322 e seguintes, pondera: "Embora a realização da chance nunca seja certa, a perda da chance pode ser certa. Por estes motivos não vemos óbice à aplicação criteriosa da teoria. O que o artigo 402 afasta é o dano meramente hipotético: mas se a vítima provar a adequação do nexo causal entre a ação culposa e ilícita do lesante e o dano sofrido (a perda da probabilidade séria e real), configurados estarão os pressupostos do dever de indenizar".
} 
A perda da chance abarca o dano existencial ou frustração de um projeto, impondo ao lesado uma reprogramação e a um relacionar-se de forma diferente no contexto sociocultural e empresarial, visto que sofreu lesão no seu direito de moldar seu destino ou de autodeterminação (NASCIMENTO, 2012, p.37-56).

A teoria da perda da chance poderá ser considerada, na nossa opinião, como uma hipótese de lucro cessante sui generis e de dano emergente sui generis, pois sem o evento danoso, a vítima poderia tirar proveito da chance, que the foi tirada, perdendo a realização de uma esperança almejada, ou seja, a possibilidade de auferir alguma vantagem, dando azo à reparação ${ }^{4}$.

Um dos grandes desafios da ciência jurídica é a determinação de critérios de quantificação de dano advindo da chance perdida, que sirvam de balizas para o Judiciário na fixação do quantum debeatur, ante a ausência de previsão legal, por meio de liquidação por arbitramento, valendo-se de perito, cujo parecer estará submetido à sua livre apreciação, podendo manter, aumentar ou diminuir o cálculo da perícia, tendo por base as demais provas constantes dos autos, o teor de contrato efetivado e os elementos do caso sub judice, levando em consideração:

a) a possibilidade de sucesso que a vítima teria por ocasião do dano sofrido, que the retirou a chance de obter ou de evitar algo;

b) o grau de culpabilidade do lesante, a gravidade e extensão da lesão (Código Civil, art. 944);

c) o caráter antissocial da conduta lesiva (Código Civil, art. 187);

d) as particularidades que afetaram a realização da vantagem pretendida;

e) a situação do lesado se a oportunidade invocada como perdida tivesse se realizado;

f) o real valor do prejuízo e do lucro cessante, fazendo uso do juízo de probabilidade ao averiguar a perda da chance;

g) os benefícios que lesante teve com seu comportamento, causando perda de uma chance ao lesado;

h) as provas firme do dano;

${ }^{4}$ Consulte: AMARAL, 2015; Enunciado n. 445 da V Jornada de Direito Civil. 
i) o critério do justum (LINDB, art. $5^{\circ}$ ), buscando a equidade, a razoabilidade e a proporcionalidade.

Como após a contratação com exclusividade, seria possível a "A" retomar a mesma posição do mercado? Tal cláusula vincula a empresa "A" à empresa "B" $\mathrm{e}$ gera indenização pela perda da chance.

Cabível será, no nosso entendimento, a indenização pela perda da chance, ante a conduta culposa da empresa "B" e o mínimo grau de probabilidade de obtenção de um lucro razoável, se não houvesse a cláusula de exclusividade.

Dever-se-á medir a chance perdida para a reparação integral de perdas e danos, tendo por parâmetro o valor do contrato.

A perda de uma chance não seria a responsabilidade da empresa "B" por dano emergente ou lucro cessante, mas por algo intermediário entre um e outro, daí falarmos em dano emergente sui generis e lucro cessante sui generis, pois refere-se à indenização pela perda da possibilidade de "A" obter uma vantagem que seria alcançada, se a empresa "B" não tivesse descumprido o contrato culposamente. A empresa "A" sofreu uma lesão às suas justas expectativas que tiveram seu fluxo normal interrompido pelo inadimplemento contratual da empresa "B". Urge uma ponderação sobre a probabilidade séria e real de obtenção da vantagem frustrada, ou seja, sobre a perda da possibilidade de auferir algum benefício, se houvesse cumprimento do contrato.

\section{PARÂMETROS PARA A QUANTIFICAÇÃO DO DANO}

Houve resolução por inexecução culposa do contrato por "B", logo, o inadimplente deverá ressarcir perdas e danos e a chance perdida.

Como a obrigação decorre do ilícito praticado pela empresa "B" é ilíquida, há necessidade de liquidação do dano causado à empresa "A", estimando-se, de acordo com o contrato e dados apurados nos eventuais autos, qual a soma correspondente cabível, que possibilite a afetiva reparação do prejuízo sofrido pela 
vítima. O órgão judicante deverá apreciar o dano integral produzido pelo fato prejudicial (damnum emergens) e o lucrum cessans, atual ou futuro.

Como se vê, do ponto de vista do conteúdo da reparação do dano, a sua liquidação poderá efetivar-se mediante indenização por equivalente que se faz em dinheiro, tendo por medida a avaliação pecuniária do dano indenizável, cuja extensão baseada no contrato, determina-se pela diferença entre a situação que a empresa " $A$ " se encontra e a situação em que se encontraria se a lesão não tivesse ocorrido.

Como há direito à reparação do dano surge a liquidação, que é a operação para sua concretização, fixando o seu montante. A aestimatio damni tem por escopo tornar líquida a obrigação de indenizar, estipulando quanto a empresa "B" deverá pagar ao lesado.

O órgão judicante, na liquidação deverá averiguar o prejuízo integral produzido pelo inadimplemento culposo da empresa "B", considerando: a) o grau de culpa do lesante (Código Civil, art. 944, parágrafo único); b) situação econômica do lesado; c) influência de acontecimentos exteriores ao fato prejudicial; d) o dano emergente, o lucro cessante e a perda de uma chance. As perdas e danos abrangerão conforme o Códig Civil, art. 402, o que "A" efetivamente perdeu e o que razoavelmente deixou de lucrar. Daí será preciso considerar se houve: dano positivo ou emergente, que consiste num déficit real e efetivo de seu patrimônio, isto é, numa concreta diminuição de sua fortuna, seja porque se depreciou o ativo, seja porque aumentou o passivo. É imprescindível que "A" tenha efetivamente experimentado um real prejuízo. Dano negativo ou lucro cessante ou frustrado, alusivo à privação de um ganho pela empresa "A", ou seja, ao lucro que ela, razoavelmente, deixou de auferir, em razão do descumprimento do contrato pela empresa "B". Para se computar o lucro cessante, recompondo o custo de oportunidade e mera probabilidade é insuficiente, embora não se exija certeza absoluta, de forma que o critério mais acertado estaria em condicioná-lo a uma probabilidade objetiva, resultante do desenvolvimento normal dos acontecimentos conjugados às circunstâncias peculiares ao caso concreto; e) lucro obtido pela empresa "A" com a reparação do dano, desde que vinculado ao fato gerador da obrigação de indenizar, 
não tendo resultado de circunstâncias fortuitas, mas sim de ato culposo; f) a apuração feita pericialmente. Se houver estipulação pericial de percentual para efeito indenizatório, com base no contrato, não há como afastá-lo, tomando-se como baliza o valor correspondente à não execução do contrato (Código Civil, 623), que foi interrompido por iniciativa de "B" antes de seu término, impedindo a empresa "A" de concluir o prometido. Considera-se razoável e justa a solução apontada no laudo pericial, no que atina ao quantum indenizatório a ser pago à empresa "A", com a devida atualização monetária que não deu causa à resilição antecipada da empreitada; g) a atualização monetária na composição das perdas e danos, consequentes de ilícito contratual, para que justa seja a indenização (Código Civil, art. 404; RT 446: 91, Súmula 562 do STF); h) a quantificação das perdas e danos sob a ótica dos arts. 389, 475 e 623, do Código Civil, deve ter por base o contrato e o art. 402 do Código Civil, pois "A" tem o direito ao que razoavelmente deixou de lucrar e pleitear a resolução do contrato; i) a chance perdida para que haja reparação integral das perda e danos (Código Civil, art. 944).

Trata-se da regra compensatio lucri cum damno.

Há liberdade de apreciação do órgão judicante, que, com prudente arbítrio, deverá examinar o inadimplemento contratual culposo, os fatos ocorridos, o conteúdo do contrato, as provas constantes nos eventuais autos e fixar a indenização a quem tem direito. Para tanto, poder-se-á recorrer ao conselho de peritos às presunções hominis, ou melhor, ao que é ditado pelas normas de experiência sob a égide do critério do boni viri.

A extensão do dano, por haver responsabilidade civil contratual deve coincidir com o valor atinente à não execução do contrato e com o recebimento integral do que "A" teria ganho se tivesse a oportunidade de concluir seus trabalhos.

Dever-se-á buscar uma solução justa à situação da empresa "A", que de nada teve culpa.

\section{CONCLUSÃO}


a) Como a responsabilidade é contratual, se o contrato existe, é esse contrato, inadimplido culposamente pela empresa "B", que deverá ser considerado para calcular o quantum indenizatório devido, abrangendo perdas e danos, ou melhor, os lucros cessantes e a oportunidade perdida. A resolução possibilitará que a empresa "A" se libere do vínculo obrigacional, para que possa livremente, celebrar outros negócios jurídicos. E com o pagamento da indenização a que faz jus, a empresa "A" ressarcir-se-á do que efetivamente perdeu, de tudo que deixou razoavelmente de lucrar (Código Civil, art. 402) e da chance perdida. ${ }^{5}$

Configurado o inadimplemento contratual culposo da empresa "B", pela não entrega do número mínimo de unidades para a construção pela empresa "A", aplicável será o art. 475 do Código Civil, determinando a resolução do contrato e indenização por perdas e danos, na forma de lucros cessantes, pois danos emergentes consistem nos custos arcados por "B" e da perda de uma chance.

Logo, inadimplemento substancial de um contrato válido e eficaz, pela empresa "B" relativamente a entrega de um número mínimo de unidades para construção pela empresa "A" é motivo para resolução contratual e de indenização pelas perdas e danos, relativa à remuneração de $16 \%$ que teria em cada obra (Código Civil, art. 475).

b) A resolução por fato imputável à empresa "B" faz operar cláusula resolutiva expressa (Código Civil, art. 474), dando ensejo à indenização por perdas e danos (Código Civil, arts. 389, 402, 475) e ao cabimento da percepção integral desses valores. $O$ inadimplemento contratual culposo dará direito à indenização das perdas e danos. O pleito indenizatório terá por parâmetro o fato de que, com o inadimplemento culposo contratual da empresa "B", houve prejuízo para a empresa "A" e consequente reparação por lucros cessantes e por perda de uma chance.

A empresa " $A$ " poderá pedir uma indenização pelos lucros cessantes, pelo que razoavelmente deixou de ganhar em razão da resolução contratual (Código Civil, art. 402 c.c art. 475), ou seja, da não entrega do número mínimo de obras. "A" apenas pleiteia o ganho de que teria em cada obra, que não the foi entregue e a

${ }^{5}$ Consulte: SZTAJNBOK, 2014. 
indenização pela perda da chance. A indenização deve ter como parâmetro o próprio contrato.

Não se terá, pela lógica do razoável, como, a priori, afastar a ideia de que viável será ação de resolução contratual cumulada com indenização por lucros cessantes e pela perda de uma chance ante o voluntário descumprimento contratual.

Justa será a resolução e a indenização por perdas e danos tendo por base econômica o contrato (Código Civil, art. 475). A indenização deverá ser apreciada, com prudência objetiva, pelo tribunal na integralidade do valor pedido pela empresa "A" ou pelo valor fixado ou levando em conta o próprio contrato, mediante liquidação, colocando a lesada na situação em que estaria caso o contrato tivesse sido cumprido.

c) A empresa "A", tendo por suporte o art. 475 do Código Civil, optou pela resolução do contrato e deixou de fazer sua contraprestação, por estar impossibilitada de cumpri-la, ante a não entrega das unidades imobiliárias prometidas. Apesar disso terá direito à percepção de uma quantia indenizatória. A indenização segundo eventual laudo pericial pela resolução decorreria dos critérios da remuneração $(16 \%)$ do valor orçado para cada obra do contrato, reparando o prejuízo de "A" no que atina ao que deixou de ganhar (Código Civil, art. 402).

Se a remuneração de " $A$ " seria o ganho líquido do contrato, com todos os custos diretos e indiretos suportados por $\mathrm{B}$, a indenização deverá dizer respeito ao que razoável e efetivamente deixou de lucrar com o descumprimento contratual.

d) A quantificação da indenização pela resolução do contrato deverá decorrer da aplicação do art. 475, Código Civil e dos critérios de remuneração do dano pelo que a empresa "A" efetivamente perdeu e por tudo que razoavelmente deixou de ganhar pelo descumprimento do contrato (Código Civil, art. 402). O que "A" deixou de ganhar com o inadimplemento culposo do contrato pela empresa "B" refletir-se-á na remuneração que foi retirada, em razão da não entrega de todas as unidades imobiliárias avençadas no contrato e na chance que perdeu em virtude de exclusividade. Logo, o parâmetro indenizatório deverá ser o valor do contrato estipulado para tal remuneração. 
Assim, o judiciário deverá, além de considerar a possibilidade de resolução contratual, averiguar, ao quantificar a indenização:

a) o valor remuneratório por cada unidade estipulado no contrato;

b) danos emergentes (se houverem);

c) lucros cessantes;

d) perda da chance;

e) culpabilidade do lesante;

f) boa-fé do lesado.

$\mathrm{O}$ art. 402 acata o princípio da razoabilidade para quantificar o lucro cessante, visto que, se certeza e atualidade são requisitos para que o dano seja indenizável, apenas se poderá considerar, para fins indenizatórios, o que razoavelmente se deixou de lucrar. Por tal razão, a perda da chance é indenizável, ante a certeza da existência da chance perdida pelo lesado por ato culposo, comissivo ou omissivo, do lesante, impedindo sua verificação.

Pagamento indevido, não haverá, pois requer enriquecimento de alguém à custa alheia, sem causa jurídica, que o justifique e sem culpa do solvens. Ora, o quantum indenizatório deverá, por isso, ser apurado com base em contrato, que, por não ter sido cumprido por culpa de "B", gerou perdas e danos. Se "A" vier a receber alguma indenização à custa da empresa "B" em razão de contrato descumprido ou de lei, não há que se falar em enriquecimento sem causa e em propositura de ação de in rem verso.

Trata-se, na verdade, de um enriquecimento permitido, que tem por suporte a ilicitude praticada pela empresa "B", geradora do dever de indenizar, pois o não permitido ou sem causa, se confina no injustificado, por haver licitude no resultado.

A boa-fé da empresa "A" terá relevância na apuração da responsabilidade indenizatória da empresa "B", e no afastamento da ideia de enriquecimento injustificado, pois a atribuição patrimonial não é sine causa.

e) A empresa "A" deverá ser ressarcida pelo que efetivamente perdeu e por tudo que razoavelmente deixou de lucrar (Código Civil, art. 402) se o contrato fosse cumprido até o término de sua vigência e, ainda, pela chance perdida, em razão da cláusula de exclusividade, pois houve inadimplemento contratual por parte 
da empresa "B". O valor da indenização deverá ter por baliza a repercussão econômica do contrato descumprido no patrimônio da empresa "A". Se for feita perícia o expert verificará o número de unidades prometidas, considerando o percentual de tolerância, menos o número das unidades contratadas, obtendo-se o número de unidades inadimplidas e deverá multiplicar o número destas últimas pela remuneração de $16 \%$, fixado no contrato. Não tomará por base o lucro líquido arbitrado para a empresa "A", porque os custos diretos e indiretos relacionados com o empreendimento, consumo de água, luz e telefone, tributos, materiais, equipamentos e mão de obra, já poderão estar incluídos no orçamento praticado pelas partes, logo serão tidos como ganho. Ora, a indenização pela perda de ganho só poderá ser estipulada tendo por critério a remuneração.

Tal remuneração representa o ganho que não teve razão do inadimplemento contratual. Além disso, o descumprimento contratual significará para a empresa "A" a perda da chance de se consolidar no país como uma das maiores construtoras com sua retirada no mercado, pois em razão de cláusula de exclusividade sofrerá consequências em seus planos futuros, não conseguindo retornar ao mercado porque as incorporadoras já estariam comprometidas com outros construtores.

Bastante razoável e adequado ao caso, por nos imaginado, será o critério apontado, que poderá ser, eventualmente, adotado pelo expert.

Diante dessa provável apuração pericial, o órgão judicante poderá, com base em seu livre convencimento e na prudência objetiva, ordenar a liquidação do quantum indenizatório, baseado no conteúdo do contrato, que deverá ser considerado como baliza econômica para a indenização a ser paga à empresa "A" pela empresa "B".

f) Poder-se-á afirmar, com rigor dogmático, que, no caso hipotético em tela, cabível será a aplicação do art. 475 do Código Civil.

g) Contrário ao princípio da boa-fé objetiva e ao da segurança das relações jurídica e, eticamente, repugnante seria 0 ato de negar a resolução contratual e a indenização à empresa "A". 
h) Visível é a pertinência da ideia, aqui apontada, pois se não puder ser acolhida haverá um desajustamento entre a realidade material dos fatos e a realidade formal das normas a eles aplicáveis.

\section{REFERÊNCIAS}

AMARAL, Ana Cláudia C. Z. M. do. Responsabilidade civil pela perda da chance. Curitiba: Juruá, 2015.

CONSOLO. II ressarcimento del danno. Milano: s/e, n. 1 e 26, 1908.

DE CUPIS, Adriano. II dano. Milano: Giuffré, 1979.

DINIZ, Maria Helena. Curso de direito civil brasileiro. São Paulo: Saraiva, v. 2, 3 e 7, 2018.

FISCHER. Los danos civiles y su reparación. Madrid: s/e, 1928.

GIORGI. Teoria dela obbligazioni. s/l: s/e, vol. 2. 1891.

GOMES, Orlando. Contratos. Rio de Janeiro: Forense, 1979.

LARENZ, Karl. Derecho de obligaciones. t. 1. 1958.

MARTINS COSTA, Judith. Comentários do novo Código Civil. Sálvio de F. Teixeira (coord.). Rio de Janeiro: Forense, vol. V, tomo III, 2003.

NASCIMENTO, Maria Emília C. do. Responsabilidade civil por dano existencial. Revista Síntese-Direito Civil e Processual Civil, 80:37-56. 2012.

PEREIRA, Caio Mário da Silva. Contrato de empreitada. RDTR, 50: 42.

POLACCO. L'obbligazioni nel direto civile italiano. s/l: s/e, vol. 1, n. 126. 1915.

PONTES DE MIRANDA. Tratado de direito privado. São Paulo: RT, t. XLIV, 1984.

SZTAJNBOK, Felipe. A indenização pelo interesse positivo como forma de tutela do interesse do credor nas hipóteses de inadimplemento culposo da obrigação. Civilística.com, Rio de Janeiro, a.3, n. 2, jul-dez/2014. Disponível em:<http://civilistica.com/a-indenização-pelo-interessepositivo-comoforma-de-tutelado-interesse-do-credor-nas-hipoteses-de-inadimplemento-culposo-da-obrigação/>. 